\title{
Validity Evidence for FASTHUG-MAIDENS, a Mnemonic for Identifying Drug-Related Problems in the Intensive Care Unit
}

\author{
Sarah C Masson, Vincent H Mabasa, Douglas L Malyuk, and Jerrold L Perrott
}

\begin{abstract}
Background: The mnemonic FASTHUG (Feeding, Analgesia, Sedation, Thromboembolic prophylaxis, Head of bed elevation, stress Ulcer prophylaxis, Glucose control) was developed by intensive care unit (ICU) physicians to ensure that key aspects of care are addressed during each patient encounter. Because this tool does not specifically target pharmacotherapy assessments, a modified version, FASTHUGMAIDENS, was created, by changing the $\mathrm{H}$ to mean Hypoactive or Hyperactive delirium and adding $\mathrm{M}$ for Medication reconciliation; A for Antibiotics or Anti-infectives; I for Indications for medications; D for drug Dosing; E for Electrolytes, hematology, and other laboratory tests; $\mathrm{N}$ for No drug interactions, allergies, duplication, or side effects; and $S$ for Stop dates.
\end{abstract}

Objective: To validate the use of FASTHUG-MAIDENS as a tool for identifying drug-related problems (DRPs) in the ICU.

Methods: This randomized, prospective validation study took place between January and May 2011 in the ICUs of 4 hospitals: 2 community-level ICUs and 2 tertiary referral ICUs. Each ICU had a dedicated ICU pharmacist and one or more pharmacy residents completing an ICU rotation as part of their pharmacy practice residency (total of 6 residents). The 6 pharmacy residents were randomly assigned to assess patients admitted to the ICU using FASTHUGMAIDENS or standard monitoring practice. The mean proportion of DRPs per patient encounter identified by the residents (relative to DRPs identified by the ICU pharmacists) was the primary outcome, and the proportion of total DRPs identified in each group was assessed as a secondary end point.

Results: Pharmacy residents using the FASTHUG-MAIDENS mnemonic identified a significantly greater mean proportion of DRPs per patient encounter $(73.2 \%$ versus $52.4 \%, p=0.008)$ and a greater proportion of total DRPs $(77.1 \%$ versus $52.5 \%, p<0.001)$ than those assessing patients according to standard monitoring practice.

Conclusion: In this sample, the mnemonic FASTHUG-MAIDENS was a useful tool to facilitate the capture of DRPs by pharmacy residents working in the ICU.

Key words: drug-related problems, intensive care unit, adverse effects, pharmacist, checklist, patient outcomes

\section{RÉSUMÉ}

Contexte : Le code mnémonique anglais FASTHUG (Feeding [alimentation], Analgesia [analgésie], Sedation [sédation], Thromboembolic prophylaxis [prophylaxie thromboembolique], Head of bed elevation [élévation de la tête du lit], stress Ulcer prophylaxis [prophylaxie des ulcères de stress], Glucose control [régulation de la glycémie]) a été imaginé par des médecins intensivistes pour s’assurer que certains aspects clés des soins sont pris en compte pour chaque consultation avec un patient. Comme cet outil ne vise pas spécifiquement les évaluations pharmacothérapeutiques, une version modifiée, FASTHUG-MAIDENS, a été créée, où l'on a remplacé le sens du $\mathrm{H}$ par Hypoactive or Hyperactive delirium (délire hypoactif ou hyperactif) et ajouté MAIDENS : Medication reconciliation (bilan comparatif des médicaments); Antibiotics or Anti-infectives (antibiotiques ou anti-infectieux); Indications for medications (indications des médicaments); drug Dosing (posologie des médicaments); Electrolytes, hematology and other laboratory tests (électrolytes, hématologie et autres épreuves de laboratoire); No drug interactions, allergies, duplication, or side effects (absence d'interactions médicamenteuses, d'allergies, de chevauchement ou d'effets secondaires); et Stop dates (dates de fin).

Objectif : Valider l'emploi du code mnémonique FASTHUG-MAIDENS comme outil pour dépister les problèmes pharmacothérapeutiques à l'unité des soins intensifs (USI).

Méthodes : Cette étude de validation aléatoire et prospective a été menée entre janvier et mai 2011 dans les USI de quatre hôpitaux : deux USI de niveau communautaire et deux autres de référence de niveau tertiaire. Chaque USI possédait un pharmacien attitré et au moins un résident en pharmacie complétant un stage à l'USI dans le cadre de leur résidence en pratique pharmaceutique (pour un total de six résidents). Les six résidents en pharmacie ont été assignés au hasard pour évaluer les patients admis à l'USI au moyen du code FASTHUG-MAIDENS ou d'une méthode de suivi standard. Le pourcentage de problèmes pharmacothérapeutiques par consultation avec un patient cernés par les résidents (comparativement à ceux constatés par les pharmaciens intensivistes) était le principal paramètre d'évaluation et le pourcentage de problèmes pharmacothérapeutiques totaux relevés dans chaque groupe était le paramètre d'évaluation secondaire.

Résultats : Les résidents en pharmacie qui ont utilisé le code mnémonique FASTHUG-MAIDENS ont cerné un pourcentage moyen significativement supérieur de problèmes pharmacothérapeutiques par consultation avec un patient $(73,2 \%$ contre $52,4 \%, p=0,008)$ et un pourcentage supérieur de problèmes pharmacothérapeutiques totaux 
$(77,1 \%$ contre $52,5 \%, p<0,001)$ que ceux qui ont évalué les patients au moyen d'une méthode de suivi standard.

Conclusion : Dans cet échantillon, le code mnémonique FASTHUGMAIDENS s'est révélé être un outil utile facilitant la détermination des problèmes pharmacothérapeutiques par les résidents en pharmacie travaillant dans une USI.

Mots clés : problèmes pharmacothérapeutiques, unité des soins intensifs, effets indésirables, pharmacien, liste de contrôle, résultats thérapeutiques

[Traduction par l'éditeur]

\section{INTRODUCTION}

$\mathrm{D}$ rug-related problems (DRPs) are issues encountered during a patient's drug therapy that potentially or actually interfere with one or more of the desired therapeutic outcomes. ${ }^{1}$ Examples of desired therapeutic outcomes include curing disease, reducing or eliminating the symptoms of disease, arresting or slowing disease progression, and preventing a disease or its symptoms. DRPs are associated with negative effects on patient outcomes and have the potential to increase the cost of care. In a recent prospective study, drug-related emergency department visits accounted for $12 \%$ of total visits, and $68 \%$ of these drug-related visits were deemed preventable. ${ }^{2}$ Furthermore, patients presenting to the emergency department with a DRP were also more likely to require hospital admission (odds ratio 2.18, 95\% confidence interval 1.46-3.27, $p<$ 0.001). According to a review of literature published between 1990 and 2005, medication-related errors occurred in association with up to $5 \%$ of all drug administrations in hospital, and more than $6 \%$ of hospital inpatients suffered adverse drug events. ${ }^{3}$ Of these errors, about $46 \%$ were judged to be preventable. Adverse drug events are not uncommon in the intensive care unit (ICU). For example, in one study of rates of adverse drug events due to prescribing errors in the ICU, the baseline event rate (before the pharmacist began participating in medical rounds) was 10.4 per 1000 patient-days. ${ }^{4}$ The presence of a pharmacist on the ICU team during medical rounds (i.e., at the time of prescribing) reduced such adverse drug events to 3.5 per 1000 patient-days, a reduction of $66 \%$ from baseline. $^{4}$

In the 1980s, Hepler and Strand ${ }^{1}$ identified 8 categories of DRPs, which they suggested as a framework for identifying both potential and actual therapy-related problems; this framework has since become known as the Hepler-Strand classification. Trained as drug experts with a specific focus on drug-related therapy, pharmacists have an important role to play on the health care team, a role that encompasses monitoring for adverse outcomes, assessing efficacy, and optimizing therapy by recommending alternatives, adding or deleting therapies, and initiating dosage adjustments.

The mnemonic FASTHUG (Feeding, Analgesia, Sedation, Thromboembolic prophylaxis, Head of bed elevation, stress Ulcer prophylaxis, Glucose control) was developed by ICU physicians to ensure that key aspects of care are addressed during each patient encounter. ${ }^{5}$ In a prospective trial comparing historical rates of ventilator-associated pneumonia with rates following implementation of the FASTHUG mnemonic, use of the mnemonic was associated with a significant decrease in event rates $(p=0.004) .{ }^{6}$ However, this tool does not specifically target pharmacotherapy assessments. Therefore, it has been modified for use by clinical pharmacists to FASTHUGMAIDENS, changing the $\mathrm{H}$ to mean Hyperactive or Hypoactive delirium and adding $\mathrm{M}$ for Medication reconciliation; A for Antibiotics or Anti-infectives; I for Indications for medications; D for drug Dosing; E for Electrolytes, hematology, and other laboratory tests; $\mathrm{N}$ for No drug interactions, allergies, duplication, or side effects; and $\mathrm{S}$ for Stop dates.

The mnemonic FASTHUG-MAIDENS can be used in a number of ways: as a quick checklist for time-challenged ICU pharmacists during care rounds, to guide non-ICU pharmacists when they are providing clinical coverage in the ICU, and as a teaching tool for students who must learn to navigate the challenging ICU environment during short rotations. ${ }^{7}$ A prospective, nonrandomized trial was conducted in 2009 to investigate the utility of the FASTHUG-MAIDENS mnemonic as a means of identifying DRPs in the ICU. In that pilot study, a pharmacy resident using the FASTHUG-MAIDENS mnemonic captured $91 \%$ of the DRPs identified by an ICU pharmacist. ${ }^{7}$ The pilot study report also provided an extensive description of the application of the tool. The study reported here, which expands on the pilot study, used standard monitoring practice as a comparator, in an attempt to quantify the benefit of the tool. It was anticipated that use of the FASTHUG-MAIDENS mnemonic would improve identification of DRPs by pharmacy residents on rotation in the ICU. 


\section{METHODS}

\section{Setting and Population}

This randomized, prospective validation study took place from January to May 2011 in the ICUs of 4 hospitals within the Fraser Health Authority in British Columbia. Ethics approval was obtained from the Fraser Health Research Ethics Board. Two of the ICUs were community-level ICUs, and 2 were tertiary referral ICUs. These sites were chosen as each had at least one pharmacy resident completing a 4-week ICU rotation during the 2010/2011 year of the Pharmacy Practice Residency Program, and each had a dedicated ICU pharmacist. All ICU rotations were completed in the latter third of the residency program, such that all residents participating in the study had a similar level of clinical experience. Each of the 6 pharmacy residents participating in this study was randomly assigned by a web-based random sequence generator to use the FASTHUG-MAIDENS mnemonic or standard monitoring practice for patient assessment. Assignments were revealed at least 2 weeks before the ICU rotation, to allow time for training, and informed consent was obtained from participating pharmacy residents as well as the ICU pharmacists who acted as preceptors. Residents received training (in use of the mnemonic or standard assessment practices) during the first 2 weeks of their ICU rotations. Data collection took place during the last 2 weeks of each resident's rotation. The ICU pharmacists represented the gold standard for patient work-ups and DRP identification. They assessed patients according to usual practice (with or without the mnemonic) and were responsible for validating DRPs identified by the pharmacy residents.

\section{Data Collection}

Data about DRPs were collected for patients admitted to the ICU and attended to by the ICU health care team during regular clinical pharmacy hours. Only patients physically located in the ICU were included, and the patients most recently admitted to the ICU were evaluated on any given day. The goal was for each pharmacy resident and ICU pharmacist to assess a minimum of 3 patients per day before patient rounds.

The DRPs identified were grouped according to the Hepler-Strand classification categories, which have been described elsewhere. ${ }^{1}$ If the pharmacy resident was using FASTHUG-MAIDENS, the DRPs were also classified in relation to the mnemonic. The data were recorded on a standard, prespecified data collection form. These forms, along with a guide for their use, were provided to both the pharmacy resident and the ICU pharmacist at least 2 weeks before the start of each rotation. The data collection forms for each patient encounter (one prepared by the resident and the other by the ICU pharmacist) were compared by the primary author
(S.C.M.), who was not involved in the data collection, to determine the DRP capture rate (i.e., the number of DRPs identified by the pharmacy resident relative to the total number of DRPs determined for each patient encounter).

\section{Outcome Measures}

The prespecified primary outcome was the mean proportion of DRPs identified for each patient encounter (i.e., DRPs identified during the work-up of a single patient on a specific day) among pharmacy residents using FASTHUG-MAIDENS and among pharmacy residents using standard monitoring practice. The overall DRP capture rate was a secondary outcome. The total number of DRPs for each patient encounter (the denominator for calculating proportions) consisted of those identified by the ICU pharmacist and any additional valid DRPs identified by the pharmacy resident.

In addition, DRPs were descriptively reported by category according to both the Hepler-Strand classification (for all patients) and the FASTHUG-MAIDENS classification (for patients assessed with the mnemonic).

\section{Sample Size}

The sample size was calculated by an independent statistician on the basis of the 2009 pilot study. ${ }^{7}$ Assuming a median effect size of 0.5 with a power of $80 \%$ and an alpha value of 0.05 , a total of 128 patient encounters would be needed: 64 patient encounters involving use of the mnemonic and 64 patient encounters involving use of standard monitoring practice.

\section{Statistical Analysis}

The Mann-Whitney $U$ test was used to compare the mean proportion of DRPs identified per patient encounter between groups, as the sample size was relatively small and did not meet the assumptions for parametric statistics. The secondary outcome, overall DRP capture rate, was analyzed with a $\chi^{2}$ test. Statistical analyses were completed by an independent statistician.

\section{RESULTS}

Three residents were assigned to use the FASTHUGMAIDENS mnemonic and three to standard monitoring practice. The primary end point, the mean proportion of DRPs identified per patient encounter, was significantly higher for patients assessed by pharmacy residents using the FASTHUGMAIDENS mnemonic $(73.2 \%$ versus $52.4 \%$; absolute difference 20.8 percentage points; $p=0.008)$. According to the secondary end point (overall DRP capture rate), pharmacy residents using the mnemonic identified significantly more of the DRPs (77.1\% [118/153] versus 52.5\% [124/236]; absolute 

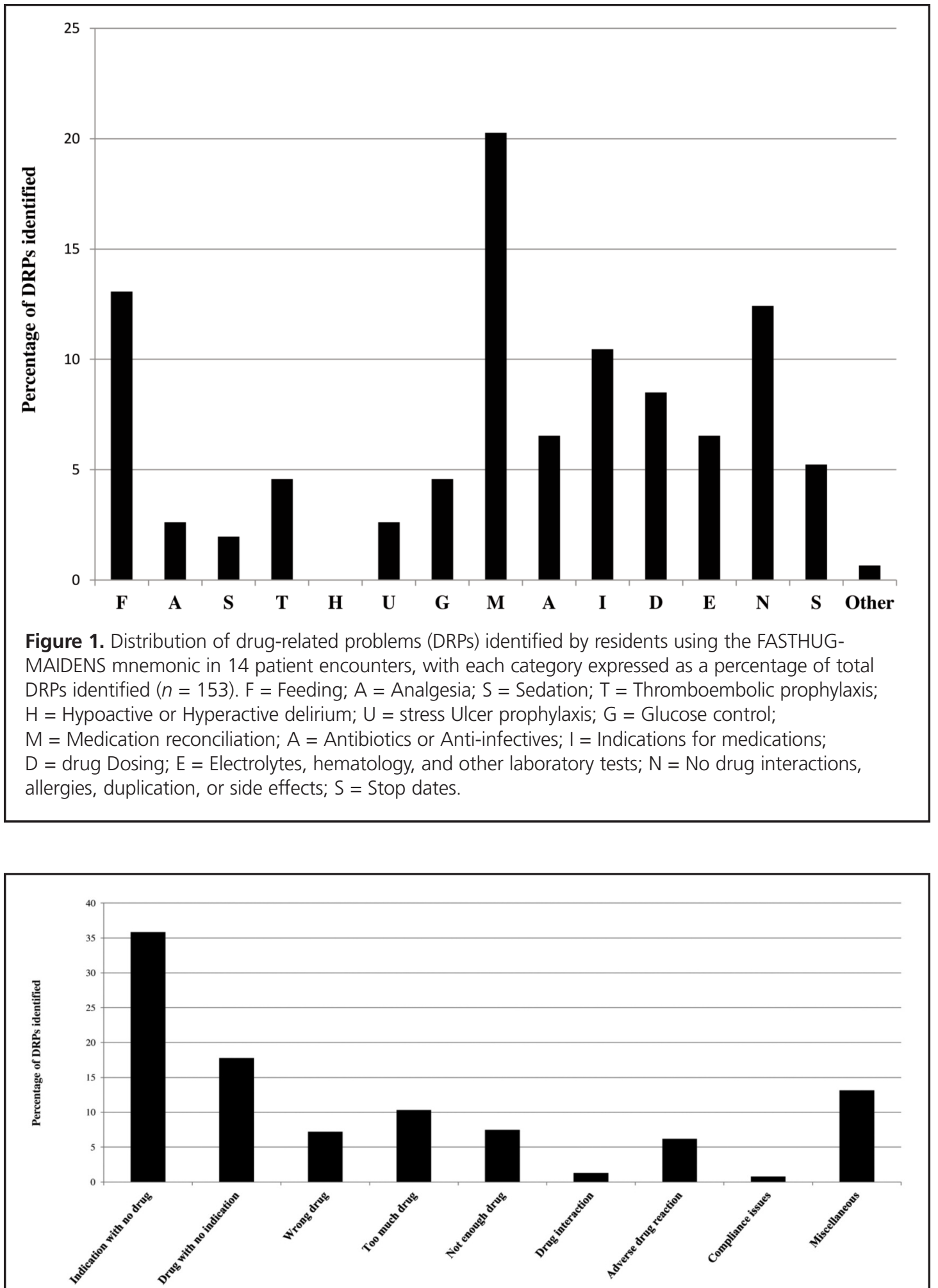

Figure 2. Distribution of all drug-related problems (DRPs) identified by both groups of residents, according to the Hepler-Strand classification, for 61 patient encounters, with each category expressed as a percentage of total DRPs identified $(n=389)$. 
difference 24.6 percentage points; $p<0.001$ ). Pharmacy residents using FASTHUG-MAIDENS performed a total of 14 patient assessments, and those using standard monitoring practice performed 47 patient assessments, for a total of 61 assessments.

Among residents using the mnemonic, DRPs related to medication reconciliation accounted for the largest group (Figure 1). When DRPs identified by both groups of residents were categorized according to the Hepler-Strand classification, the presence of an indication with no drug therapy accounted for the largest category (Figure 2). Miscellaneous DRPs identified when using the Hepler-Strand classification were related to IV to oral step-down of medications (e.g., antibiotics, proton pump inhibitors, histamine-2 receptor antagonists), stop dates for antimicrobials, therapeutic duplications, drug monitoring (e.g., drug levels), and assessment of feeding status. Only one DRP identified using the FASTHUG-MAIDENS mnemonic was categorized as "miscellaneous", the requirement for an at-home asthma action plan.

\section{DISCUSSION}

Use of the FASTHUG-MAIDENS mnemonic improved identification of DRPs by pharmacy residents in the ICU. This outcome was statistically significant even though workload constraints at some sites prevented pharmacy residents, especially those in the FASTHUG-MAIDENS group, from performing the predetermined number of patient assessments. We argue that the mnemonic would also be of benefit in other areas of practice, as many of the issues identified with the mnemonic occur in care settings other than the ICU. We also encourage use of the FASTHUG-MAIDENS mnemonic as a tool for training new pharmacists or pharmacy residents in the ICU.

We have descriptively reported the classification of DRPs according to the Hepler-Strand framework and the FASTHUG-MAIDENS mnemonic. The most commonly identified DRPs according to the Hepler-Strand classification were "indication, no drug" and "drug, no indication". This finding indicates that pharmacists have a strong role to play in recommending the initiation of therapies and the discontinuation of unnecessary drug treatments. According to the FASTHUG-MAIDENS mnemonic, the most commonly identified DRPs were related to medication reconciliation, feeding (which includes assessing whether or not feeding should be initiated or changed, as well as changing routes of drug administration from IV to PO or vice versa), and assessment for interactions, allergies, duplications, and side effects. Interestingly, no cases of delirium were seen during data collection, despite the fact that this is a common and clinically significant outcome of admission to an ICU. ${ }^{8,9}$ This may be because the study protocol specified that only newly admitted patients be assessed, whereas delirium tends to occur after a prolonged stay in the ICU.

The FASTHUG-MAIDENS mnemonic expands on the Hepler-Strand classification in 2 key ways, by specifically addressing medication reconciliation and antimicrobial stewardship, both of which are Required Organizational Practices set out by Accreditation Canada. ${ }^{10,11}$ Performing medication reconciliation ensures that drug therapies (e.g., antihypertensives, antidepressants, medications for diabetes mellitus) are assessed and changes are communicated across transitions of care (e.g., after admission to and discharge from the hospital) and reduces the risk of duplicate therapy and drug interactions. ${ }^{10}$ Antimicrobial stewardship promotes positive clinical outcomes, reduces adverse effects, and limits selection for pathogenic organisms such as Clostridium difficile and drugresistant organisms such as extended-spectrum ß-lactamase producers. ${ }^{12}$ The Infectious Diseases Society of America has cited antimicrobial stewardship as "an essential part of patient safety" and considers a clinical pharmacist with infectious disease training to be an essential component of a multidisciplinary antimicrobial stewardship team. ${ }^{12}$ In addition to improvements in patient outcomes, antimicrobial stewardship is often associated with cost savings, and it encourages narrowing of the spectrum of activity and stepping down from IV to oral routes of administration when clinically appropriate.

The utility of mnemonics or checklists in the ICU has been previously documented. A recent cohort study in a medical ICU was designed to compare a checklist alone against the same checklist combined with verbal prompting in terms of improvements in relevant patient outcomes. ${ }^{13}$ Verbal prompting consisted of delivering scripted questions to the primary caregiver when the rounding care team failed to address key parameters being investigated in the trial. Although implementation of the checklist on its own was not associated with better outcomes, use of the checklist in conjunction with verbal prompting increased median ventilator-free days, decreased the length of empiric antibiotic therapy, decreased duration of central venous catheterization, and increased rates of compliance with therapies for deep vein thrombosis prevention and stress ulcer prophylaxis. Use of the checklist with verbal prompting also decreased risk-adjusted ICU mortality, risk-adjusted hospital mortality, and observed-to-predicted ICU length of stay relative to control. A pharmacist on the ICU team using the FASTHUG-MAIDENS mnemonic could certainly act as the verbal prompter for daily review of relevant patient care interventions.

\section{Limitations}

This study had several limitations. The level of patient acuity differed among the various sites, and we cannot be sure that the patients assessed with the 2 methods had similar levels 
of acuity. We did not obtain Acute Physiology and Chronic Health Evaluation II (APACHE II) scores or other measures of disease severity for comparison. Randomization of the pharmacy residents themselves would do little to control for this inter-patient and inter-site variability. Ideally, the patients, rather than the residents, would have been randomized for assessment by standard monitoring practice or the mnemonic, or each patient would have been assessed by 2 different individuals, each using a different modality. This issue might have been mitigated if there had been more than 3 pharmacy residents in each group or if the preset sample size of 64 patient encounters in each group had been met. Unfortunately, expanding the study to include a greater number of residents was not possible within the resources available for this study. In addition, further data collection will not be possible, as the initial pilot study is now in print, ${ }^{7}$ and we can no longer assume that pharmacy residents are not familiar with the FASTHUGMAIDENS mnemonic; we do acknowledge that further data collection would be ideal to enhance the robustness of the results. Finally, we cannot rule out the possibility that residents discussed their ICU rotations with those who had not yet completed their rotations, which might have led to better performance among residents who completed the ICU rotation later in the year relative to those who completed the ICU rotation earlier (or better performance than would otherwise have been the case).

\section{CONCLUSIONS}

In this sample, the FASTHUG-MAIDENS mnemonic was a useful aid to pharmacy residents in identifying DRPs in the ICU. Compared with standard monitoring practice, a greater proportion of DRPs per patient encounter and a greater proportion of total DRPs were identified by pharmacy residents using this mnemonic.

\footnotetext{
References

1. Hepler CD, Strand LM. Opportunities and responsibilities in pharmaceutical care. Am J Hosp Pharm. 1990;47(3):533-43.

2. Zed PJ, Abu-Laban RB, Balen RM, Loewen PS, Hohl CM, Brubacher JR, et al. Incidence, severity and preventability of medication-related visits to the emergency department: a prospective study. CMAJ. 2008;178(12):1563-9.

3. Krähenbühl-Melcher A, Schlienger R, Lampert M, Haschke M, Drewe J, Krähenbühl S. Drug-related problems in hospitals: a review of the recent literature. Drug Saf. 2007;30(5):379-407.

4. Leape LL, Cullen, DJ, Clapp MD, Burdick E, Demonaco HJ, Erickson JI, et al. Pharmacist participation on physician rounds and adverse drug events
}

in the intensive care unit. JAMA. 1999;282(3):267-70. Erratum in: JAMA. 2000;283(10):1293.

5. Vincent JL. Give your patient a fast hug (at least) once a day. Crit Care Med. 2005;33(6):1225-9.

6. Papadimos TJ, Hensley SJ, Duggan JM, Khuder SA, Borst MJ, Fath JJ, et al. Implementation of the "FASTHUG" concept decreases the incidence of ventilator-associated pneumonia in a surgical intensive care unit. Patient Saf Surg [serial on Internet] 2008 [cited 2010 Jul 26];2(3). Available from: www.pssjournal.com/content/2/1/3

7. Mabasa VH, Malyuk DL, Weatherby EM, Chan A. A standardized, structured approach to identifying drug-related problems in the intensive care unit: FASTHUG-MAIDENS. Can J Hosp Pharm. 2011;64(5):366-9.

8. Ely EW, Shintani A, Truman B, Speroff T, Gordon SM, Harrell FE Jr, et al. Delirium as a predictor of mortality in mechanically ventilated patients in the intensive care unit. JAMA. 2004;291(14):1753-62.

9. Girard TD, Pandharipande PP, Ely EW. Delirium in the intensive care unit. Crit Care. 2008;12 Suppl 3:S3.

10. Accreditation Canada, Canadian Institute for Health Information, Canadian Patient Safety Institute, Institute for Safe Medication Practices Canada. Medication reconciliation in Canada: raising the bar-progress to date and the course ahead. Ottawa (ON): Accreditation Canada; 2012 [cited 2012 Nov 29]. Available from: www.accreditation.ca/uploadedFiles/Medication $\%$ 20reconciliation\%2010\%2031\%202012.pdf

11. Required organizational practices 2012. Ottawa (ON): Accreditation Canada; 2012 [cited 2013 Jan 7]. Available from: www.accreditation.cal uploadedFiles/ROP\%20Handbook.pdf

12. Dellit TH, Owens RC, McGowan JE Jr, Gerding DN, Weinstein RA, Burke JP, et al. Infectious Diseases Society of America and the Society for Healthcare Epidemiology of America guidelines for developing an institutional program to enhance antimicrobial stewardship. Clin Infect Dis. 2007:44(2):159-77.

13. Weiss CH, Moazed F, McEvoy CA, Singer BD, Szleifer I, Amaral LA, et al. Prompting physicians to address a daily checklist and process of care and clinical outcomes: a single-site study. Am J Respir Crit Care Med. 2011; 184(6):680-6.

Sarah C Masson, BSCPharm, ACPR, is with the Abbotsford Regional Hospital, Abbotsford, British Columbia.

Vincent $\mathbf{H}$ Mabasa, BScPharm, ACPR, PharmD, is with the Burnaby Hospital, Burnaby, British Columbia.

Douglas L Malyuk, BSCPharm, ACPR, PharmD, is with the Royal Columbian Hospital, New Westminster, British Columbia.

Jerrold L Perrott, BSCPharm, ACPR, PharmD, is with the Royal Columbian Hospital, New Westminster, British Columbia.

Competing interests: None declared.

Address correspondence to:

Sarah C Masson

Abbotsford Regional Hospital

32900 Marshall Road

Abbotsford BC V2S OC2

e-mail: sarah.masson@fraserhealth.ca 